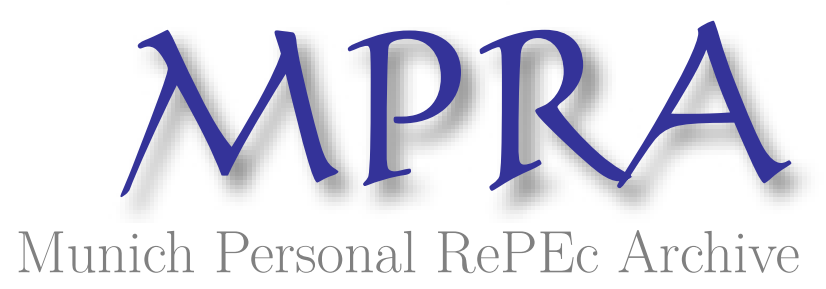

\title{
Australian telephone network subscription and calling demands: evidence from a stated-preference experiment
}

Madden, Gary G and Bloch, Harry and Hensher, David

Curtin University of Technology, Perth, Australia

1993

Online at https://mpra.ub.uni-muenchen.de/10681/

MPRA Paper No. 10681, posted 22 Sep 2008 09:36 UTC 


\title{
Australian telephone network subscription and calling demands: evidence from a stated-preference experiment
}

\author{
Gary Madden \\ Curtin University of Technology, Perth, WA 6000, Australia
}

Harry Bloch

University of Tasmania, Hobart, TAS 7000, Australia

\section{David Hensher}

University of Sydney, Sydney, NSW 2000, Australia

This paper examines the impact of the subscription-calling rate structure on the demand for residential telephone network subscription and calling. Stated-preference experimental data are used to estimate demand equations. The results indicate that household network subscription and calling demands for the Sydney Metropolitan Area are affected by both rate structure and household socio-demographic variables.

Keywords: Telecommunications demand; Subscription-calling rate structure; Stated-preference experimental analysis; Survey

JEL Classification: D12; L96

\section{Introduction}

The Australian telecommunications subscription-calling rate structure has developed in a monopolistic environment. Cross-subsidies in the rate structure have contributed to pressure for a competing telecommunications

Correspondence to: G. Madden, Curtin University of Technology, GPO Box U1987, Perth, WA 6001, Australia.

The authors acknowledge the assistance received from Helen Battellino of National Survey Research Pty Ltd in conducting the telephone use survey of network subscribers. Any opinions, findings, conclusions, or recommendations expressed in this paper are those of the authors. 
carrier to encourage the market provision of an optimal (efficient) rate structure.' A major problem for carriers in designing optimal rate structures is that little is known of consumer subscription-calling response to changes in prices.

Previous studies of residential telephone demand (Mitchell, 1978; Pacey, 1983; Park et al., 1983; Taylor and Kridel, 1990) separately explain regional call traffic revenues and telephone network penetration rates in terms of regional income and call-price indices. ${ }^{2}$ These studies ignore the interdependence of individual telephone network subscription and telephone calling demands as established by Squire (1973). Further, the effects of variables that carriers control, such as the rate structure over calling distance or timing of calls, are excluded from the analyses. Any temporal call substitution that may exist is ignored.

A framework is developed in the present paper for conducting telecommunications stated-preference (or conjoint) pricing experiments to enable the evaluation of consumer response to alternative rate structures and determine the associated expenditure. Building on the notion that houschold telephone calling demand is a vector of call-minutes corresponding to separately priced distance-time bands, stated-preference methods provide a set of experimental call-minute price regimes. Survey respondents specify conditional household call-minute demands corresponding to a price vector generated by a fractional factorial experiment applied to the set of experimental price regimes. After specifying the conditional demands the respondent then indicates whether household network subscription is maintained at the experimental line rental charge.

The paper is organised as follows. The received telephone demand theory is described and extended to the vector case in Section 2. In Section 3, the estimable model and econometric method are specified. Section 4 provides a description of the stated-preference data generation method and the survey procedures. A discussion of the estimation results is provided in Section 5.

\section{The model}

The demand for telephone network subscription and calling is jointly determined. In this scetion the received theory (Squire, 1973) is extended to the individual choice of subscription level and calling portfolio. An

\footnotetext{
${ }^{1}$ On 8 November 1990 the Australian Government announced its decision to establish a private sector competitor (Optus Communications) to a merged Telecom/OTC (AOTC) in the provision of network facilities.

${ }^{2}$ Several recent attempts model the demand for residential service choice and the demand for local calling use cross-sectional micro-level survey data (e.g, Kling and Van Der Ploeg 1990; Atherton et al., 1990; Train et al., 1987).
} 
econometrically testable model consistent with the extended formulation is specified by linking the model to a continuous/discrete choice framework.

\subsection{Received theory}

Consider a telephone network that serves an area populated by $N$ households. Each household faces a discrete network subscription decision and a choice of how many fixed price telephone calls to make. Assume household $i$ utility is a function of the number of calls made $(q)$ and amount of other goods $(\boldsymbol{x})$ consumed,

$$
u_{i}=u_{i}(q, x)
$$

where $q$ takes the value 0 (no network subscription) or $>0$ (single line rental network subscription) and $\boldsymbol{x}$ is an $n$-dimensional vector. Utility is assumed strictly quasi-concave in $q$ and $\boldsymbol{x}$.

Because the subscription choice can involve a corner solution, the problem is formulated as a two-stage process. The household is assumed to select a subscription alternative. Values of $q$ and $\boldsymbol{x}$ are then chosen to maximise (1) subject to the household budget constraint,

$$
p x+\delta\left(r+p_{c} q\right)=y_{i}
$$

where $\boldsymbol{p}$ is a vector of prices for other goods, $r$ is the line rental (subscription) fee, $p_{c}$ is the price per call and $y_{i}$ is household $i$ money income. The parameter $\delta=1$ if the household subscribes to the network; $\delta=0$ otherwise. ${ }^{3}$

The utility maximisation problem for any household implies a maximum value of the subscription fee $r_{i}^{*}$ that leaves the household indifferent as to whether to subscribe. Solving explicitly for $r_{i}^{*}$,

$$
r_{i}^{*}=\psi_{i}\left(\boldsymbol{p}, p_{c}, y_{i}\right)
$$

provides the subscription reservation-price function for household $i$. Assuming that free subscription is preferred to no network access, $0<r_{i}^{*} \leqslant y_{i}, \psi_{i}$ is homogeneous of degree one in $\boldsymbol{p}, p_{c}$ and $y_{i}$ under the assumption that $v_{i}(\boldsymbol{p}$, $\left.p_{c}, y_{i}-r_{i}^{*}\right)$ is homogeneous of degree zero.

Suppose $r_{i}^{*}$ varies according to some probability density $h\left(r_{i}^{*}\right)$. If $r$ is the single line rental subscription fee then household $i$ subscribes if and only if $r_{i}^{*} \geqslant r$. Denote $N_{1}$, the number of telephone subscribers in the population.

\footnotetext{
${ }^{3}$ If $\delta=0$ then $q=0$. That is, if the household decides not to access the network then no calls are made.
} 
Telephone network subscription penetration, $n=N_{1} / N$, is

$$
n=\int_{r}^{\infty} h\left(r_{i}^{*}\right) \mathrm{d} r_{i}^{*}
$$

Further, assume the distribution of reservation prices is

$$
\log r_{i}=\phi\left(p, p_{c}, \bar{y}\right)+\varepsilon_{i}
$$

where $\varepsilon_{i}$ is distributed extreme value with mean equal 0 and variance equal $\sigma^{24}$ Then $\log r_{i}^{*}$ is distributed logistic with mean $\phi\left(p, p_{c}, \bar{y}\right)$ and variance $\sigma^{2}$. The probability density is

$$
h\left(Z^{*}\right)=\frac{\exp \left(Z^{*}\right)}{\tau\left[1+\exp \left(Z^{*}\right)\right]^{2}},
$$

where $Z^{*}=\left[\log r_{i}^{*}-\phi\left(p, p_{c}, \bar{y}\right)\right] / \tau$ and $\tau=\sqrt{3} / \pi$. With subscription fee $r$ charged, the penetration rate is

$$
\begin{aligned}
n & =\operatorname{prob}\left(r_{i}^{*} \geqslant r\right) \\
n & =\int_{Z}^{\infty} h\left(Z^{*}\right) \mathrm{d} Z^{*} \\
& =\frac{1}{1+\exp (Z)},
\end{aligned}
$$

where $Z=\left[\log r-\phi\left(p, p_{c}, \bar{y}\right)\right] / \tau$.

\subsection{Received theory: an extension}

The received theory establishes the interdependence of telephone network subscription and calling demand in that household subscription-calling decisions are influenced by both the price per call and the line rental charge. However, the choice set is unduly restricted. Here the choice set is expanded in two ways. First, the line rental alternatives include no network subscription, single line rental subscription, subscription with two rental lines and so on. Sccond, the individual chooses a number of call-minutes $\left(m_{i j}^{d, t}\right)$ in several distance-time bands, so that his calling portfolio is defined as a particular number of call-minutes for each distance-time calling band.

Formal derivation of the extended model follows Dubin and McFadden

\footnotetext{
${ }^{4}$ In general households differ both in income and preferences. To illustrate how the presented theory can generate logit probabilities we assume $y_{i}=\bar{y} \forall_{i \in N}$. We could have just as easily assumed identical preferences with household income distributed logistically.
} 
(1984) and Dubin (1985). Household $i$ faces the set $J$ of mutually exclusive, exhaustive subscription alternatives. Subscription alternative $j$ has a line rental fee, $r_{j}$, with $r_{0}=0$. Label the observed characteristics of each alternative $j$ in $J$ as $z_{j}^{0}$, household income as $y_{i}$, other observed characteristics of the household as $s_{i}^{0}$, and all unobserved factors as $w_{i j}$. The callminute price, denoted as $p_{c}^{d, t}$, is an element of the call-minute price vector $p_{c}$.

The maximum attainable utility for alternative $j$ in $J$ is given by

$$
v_{i j}=v_{i j}\left(\boldsymbol{p}_{c}, y_{i}-r_{j}, z_{j}^{0}, s_{i}^{0}, w_{i j}\right) .
$$

The household selects alternative $j$ if and only if

$$
\begin{aligned}
& v_{i j}\left(\boldsymbol{p}_{c}, y_{i}-r_{j}, z_{j}^{0}, s_{i}^{0}, w_{i j}\right) \\
& >v_{i k}\left(\boldsymbol{p}_{\mathrm{c}}, y_{i}-r_{k}, z_{k}^{0}, s_{i}^{0}, w_{i k}\right), \quad \forall_{k \in J}, k \neq j .
\end{aligned}
$$

The corresponding choice probability for alternative $j$ is

$$
\begin{aligned}
P_{i j}= & \operatorname{Prob}\left[v_{i j}\left(\boldsymbol{p}_{c}, y_{i}-r_{j}, z_{j}^{0}, s_{i}^{0}, w_{i j}\right)\right. \\
& \left.>v_{i k}\left(\boldsymbol{p}_{c}, y_{i}-r_{k}, z_{k}^{0}, s_{i}^{0}, w_{i k}\right) \quad \forall_{k \in J}, k \neq j\right] .
\end{aligned}
$$

To specify closed-form probabilities requires that indirect utility is partitioned as follows:

$$
v_{i j}=v_{i j}\left(\boldsymbol{p}_{c}, y_{i}-r_{j}, z_{j}^{0}, s_{i}^{0}\right)+e_{i j}
$$

where $e_{i j}=e_{i j}\left[w_{i j}\left(z_{j}^{u}, s_{i}^{u}\right)\right] . v_{i j}$ is the representative indirect utility of household $i$ for alternative $j$. With $e_{i j}$ distributed extreme value, the closed-form subscription probabilities are logit in $v_{i j}$ such that

$$
P_{i j}=\frac{\exp \left[v_{i j}\left(\boldsymbol{p}_{c}, y_{i}-r_{j}, z_{j}^{0}, s_{i}^{0}\right)\right]}{\sum_{k \in J} \exp \left[v_{i k}\left(\boldsymbol{p}_{c}, y_{i}-r_{k}, z_{k}^{0}, s_{i}^{0}\right)\right]} .
$$

\footnotetext{
${ }^{5}$ The MNL model in (11) differs from the reservation price model in (5) in the rationale for $e_{i j}$. In the MNL model individuals differ only in their personal characteristics and the importance they place on an alternative's characteristics. Individuals do not differ in the manner in which they substitute between characteristics, that is, individuals share the same parameterisation of utility. In this case $e_{i j}$ represents unobserved factors (to the analyst) in each trial. The reservation price model places no such restrictions on individual behaviour. With all individual and product characteristics observed, $e_{i}$ reflects differences in the shape of the individual utility surface. When the distribution over the economy of unobserved characteristics coincides with that of utility surfaces, penetration rates will coincide.
} 
The demand for $m_{i j}^{d, t}$ is determined from the conditional indirect utility functions using Roy's identity. That is:

$$
\begin{aligned}
m_{i j}^{d, t} & =-\frac{\partial v_{i j}\left(\boldsymbol{p}_{c}, y_{i}-r_{j}, z_{j}^{0}, s_{i}^{0}, w_{i j}\right) / \partial p_{c}^{d, t}}{\partial v_{i j}\left(\boldsymbol{p}_{c}, y_{i}-r_{j}, z_{j}^{0}, s_{i}^{0}, w_{i j}\right) / \partial\left(y_{i}-r_{j}\right)} \\
& =m_{i j}^{d . t}\left(\boldsymbol{p}_{c}, y_{i}-r_{j}, z_{j}^{0}, s_{i}^{0}, w_{i j}\right) .
\end{aligned}
$$

The conditional demands in (13) depend both on obscrved and unobserved factors.

\section{Econometric method}

The subscription-calling demand system $[(12),(13)]$ is operationalised by separating representative and random utility as in (11). The equation (13) error structure depends on how $w_{i j}$ enters $m_{i j}^{d, t}$. Random utility is assumed distributed extreme value, while the arguments and a mathematical form of representative utility and the call demand equations are specified below.

\subsection{Econometric model specification}

Decomposition of the indirect utility through (11) provides the subscription probabilities,

$$
\begin{aligned}
P_{i j}= & \operatorname{Prob}\left[\boldsymbol{e}_{i k}-e_{i j}<v_{i j}\left(\boldsymbol{p}_{c}, y_{i}-r_{j}, z_{j}^{0}, s_{i}^{0}\right)\right. \\
& \left.-v_{i k}\left(\boldsymbol{p}_{c}, y_{i}-r_{k}, z_{k}^{0}, s_{i}^{0}\right) \text { for } k \neq j, k-0, \ldots, J\right],
\end{aligned}
$$

and implies that the calling demands obtained through (13) are of the form:

$$
m_{i j}^{d, t}=m_{i j}^{d, t}\left(\boldsymbol{p}_{c}, y_{i}^{0}-r_{j}, z_{j}^{0}, s_{i}^{0}\right)
$$

The continuous/discrete demand specification $(14,15)$ requires that the explicit functional forms for call-minute demands and indirect utility are compatible, because $v_{i j}$ and $m_{i j}^{d, t}$ are connected through (13). The scarch for an eligible utility model is further restricted by the maintained hypothesis employed in continuous/discrete demand models, that discrete alternatives are mutually exclusive goods.

Dubin (1985) satisfies the conditions in solving linear durable utilisation demands to find the compatible indirect utility function as follows:

$$
v\left(p_{1}, \ldots, p_{n}, y\right)=\left[\exp \left(-\Sigma \beta_{j} p_{j}\right)\right] \cdot\left[y+M\left(p_{1}, p_{2}, \ldots, p_{n}\right)\right],
$$


where

$$
M-\int_{p_{1}} \exp \left(\beta_{1}\left(p_{1}-t\right)\right) \cdot M_{1}\left(t, p_{2}, \ldots, p_{n}\right) \mathrm{d} t,
$$

satisfies Slutsky symmetry restrictions: ${ }^{6}$

$$
\beta_{j} M-\frac{\partial M}{\partial p_{2}}=M_{j} \quad \text { for } j=1,2, \ldots, n .
$$

Here call-minute demands (15) are considered in a system where $m_{i j}^{d, t}$ is linear in $\left(y_{i}-r_{j}\right)$, alternative $j$ characteristics and household $i$ characteristics, viz.,

$$
m_{i j}^{d, t}=M_{i j}\left(\boldsymbol{p}_{c}\right)+\beta_{i j}\left(y_{i}-r_{j}\right)+f\left(z_{j}^{0}, s_{i}^{0}\right),
$$

where $M_{i j}$ and $f$ are vector-valued functions and $\beta_{i j}$ is a scalar parameter.

A special case of the indirect utility function considered by Dubin and McFadden (1984) and Train (1986),

$$
\begin{aligned}
v_{i j}= & \ln \left[\left(\alpha_{i j}+\boldsymbol{\theta}_{i j} \boldsymbol{p}_{c}+\beta_{i j}\left(y_{i}-r_{j}\right)\right.\right. \\
& \left.+\psi_{i j} f\left(z_{j}^{0}, s_{i}^{0}\right) \cdot \exp \left(-\beta_{i j} p_{c}^{d, t}\right)\right],
\end{aligned}
$$

provides the call demands:

$$
\begin{aligned}
m_{i j}^{d, t}= & {\left[\alpha_{i j}-\left(\theta_{i j} / \beta_{i j}\right)\right]+\boldsymbol{\theta}_{i j} p_{c}+\beta_{i j}\left(y_{i}-r_{j}\right) } \\
& +\psi_{l j} f\left(z_{l}^{0}, s_{l}^{0}\right)+e_{i j} .
\end{aligned}
$$

There is no variation in $\beta_{i j} p_{c}^{d, t}$ over $(i, j)$, so household $i$ ignores the value in comparing $v_{i j}$ and $v_{i k}$. Therefore, the probability that household $i$ subscribes $j$ rental lines is,

$$
P_{i j}=\operatorname{Prob}\left(v_{i j}+e_{i j}>v_{i k}-e_{i k} \text { for all } k \text { in } J, k \neq j\right),
$$

where $v_{i j}=\alpha_{i j}+\boldsymbol{\theta}_{i j} \boldsymbol{p}_{\mathrm{c}}+\beta_{i j}\left(y_{i}-r_{j}\right)+\psi_{i j}\left(z_{j}^{0}, s_{i}^{0}\right)$.

Economic theory suggests call demands (15) vary with the $p_{c}^{d . t}$ in $p_{c}$. Because within a distance band temporal call substitution is plausible, the magnitude of the cross price clasticities necd to be determined. However, for convenience call substitution over other distance bands is assumed

${ }^{6}$ Additional integrability restrictions (homogeneity, summability, non-negativity, and negative quasi-semi-definiteness) are imposed on $M$ by the requirement that $v\left(p_{1}, p_{2}, \ldots p_{n}, y\right)$ be an indirect utility function. 
implausible, and variation in their price acts through the budget constraint. Equations (21) are specified,

$$
m_{i j}^{d, t}=\gamma_{i j}^{d, t}+\sum_{t} \theta_{i j}^{d, t} p_{c}^{d, t}+\beta_{i j}^{d, t}\left(y_{i}-r_{j}\right)+\psi_{i j}^{d, t} \bar{f}\left(s_{i}^{0}\right)+e_{i j}^{d, t},
$$

where $d$ and $t$ refer to five distance bands and three time zones, respectively.?

\subsection{Sequential econometric estimation method}

The random drawing of $(j, m, s)$ combinations from the joint distribution of telephone line rental choice, household calling and household characteristics define the sample likelihood,

$$
\mathscr{L}^{*}(\theta)=\prod_{\tau} \prod_{m} \prod_{j} f(j, \boldsymbol{m}, s)^{y_{\tau j}}
$$

where $f(j, \boldsymbol{m}, s)$ is the joint distribution of the telephone choice experiment responses and household characteristics in the single telephone line market segment, while the $(0,1)$ variable $y_{\tau j}$ indicates the number of telephone lines rented by household $i$ in trial repetition $\tau$. The joint distribution of experimental choices and household characteristics are decomposed as follows:

$$
\begin{aligned}
f(j, \boldsymbol{m}, \boldsymbol{s}) & =P(j \mid \boldsymbol{m}, \boldsymbol{s}, \boldsymbol{\theta}) p(s) \\
& =P(j \mid \boldsymbol{m}(s), \boldsymbol{s}, \boldsymbol{\theta}) p(s) \\
& =P(j \mid s, \boldsymbol{\theta}) p(s)
\end{aligned}
$$

The associated log likelihood function,

$$
\begin{aligned}
\mathscr{L} & =\sum_{\tau} \sum_{j} y_{\tau j} \ln P\left(k \mid s_{\tau}, \boldsymbol{\theta}\right)+\sum_{\tau} \ln p\left(\boldsymbol{s}_{\tau}\right) \\
& =\sum_{\tau} \sum_{j} y_{\tau j}\left(\boldsymbol{\theta}^{T} \boldsymbol{s}_{\tau j}-\ln \sum_{j} \exp \left(\boldsymbol{\theta}^{T} \boldsymbol{s}_{\tau j}\right)\right)+\sum_{\tau} \ln p\left(\boldsymbol{s}_{\tau}\right),
\end{aligned}
$$

for linear-in-parameters logit choice probabilities. McFadden (1974) proves

\footnotetext{
${ }^{7}$ The following distance-time calling bands are used for the empirical analysis: Day, 0-10 km; Night, 0-10 km; Day, 10-30 km; Night, 10-30 km; Day, 30-100 km; Night, 30-100 km; Economy, 30-100 km; Day, 100-800 km; Night, 100-800 km; Economy, $100-800 \mathrm{~km}$; Day, Over $800 \mathrm{~km}$; Night, Over $800 \mathrm{~km}$; Economy, Over $800 \mathrm{~km}$. The Over $800 \mathrm{~km}$ time zones are 8 am through $6 \mathrm{pm}$ Monday through Saturday, $6 \mathrm{pm}$ through $10 \mathrm{pm}$ Monday through Friday and $10 \mathrm{pm}$ through 8 am everyday and $6 \mathrm{pm}$ Saturday through 8 am Monday, respectively.
} 
that $\mathscr{L}$ is globally concave in $\boldsymbol{\theta}$ and that the ML estimator $\boldsymbol{\theta}$ is consistent and asymptotically normal. ${ }^{8}$

The five distance bands and three time zones define thirteen intraAustralian distance-time calling bands. Thirteen estimable subscription conditional call minute demand equations are associated with the discrete option of subscription with single line rental. Estimating the conditional calling demand equations separately using OLS or when grouped by calling time and distance band using a systems method, provides biased and inefficient parameter estimates. The selection bias arises from unobserved factors that influence both the household line rental choice and household calling pattern decisions. Formally, the expectation of the random error term in the $(d, t)$ th calling demand equation, conditioned on the event that $k$ lines are rented, is not zero,

$$
E\left(e_{i k}^{u, t}\right)=E\left(e_{i j}^{d, r} \mid j=k\right) \neq 0
$$

for all $j, k$ in $J$. The random error term in $(d, t)$ th calling demand is decomposed,

$$
e_{i k}^{d, t}=E\left(e_{i j}^{d, t} \mid j=k\right)+\eta_{i}^{d, t}
$$

where $E\left(\eta_{i}^{d, t}\right)=0$ and $\operatorname{correl}\left(\eta_{i}^{d, t}, E\left(e_{i j}^{d, t} \mid j=k\right)\right)=0$.

Unbiased conditional calling demand equation parameter estimation follows from applying the conditional expectation correction to either separate OLS estimation of household calling demand equations on the subsample that choose to rent $k$ lines, using,

$$
E\left(e_{i j}^{d, t} \mid j=k s\right)=\sum_{\substack{j \in J \\ k \neq j}}^{J}\left[\frac{\sigma \sqrt{6} R_{i j}}{\pi}\right]\left[\frac{P_{i j} \ln P_{i j}}{1-P_{i j}}+\ln P_{i k}\right],
$$

as a consistent estimate for $E\left(e_{i j}^{d, t} \mid j=k\right)$ or by applying SUR estimation to calling demand equations on the entire sample. SUR estimation of the equations is more efficient than OLS applied separately to the conditional calling demand equations because cross-equation disturbance correlation is present. The correlation between disturbance terms over other distance bands arises from price variations affecting other calling demands through the budget constraint.

\footnotetext{
${ }^{8}$ Computational efficiency is lost when ML methods are applied to data assuming each observation is separate, when each individual is observed repeatedly while attributes of alternatives remain constant. Ben-Akiva and Lerman (1985) detail computationally efficient weighted ML procedures. The procedures are not appropriate here because although each individual is observed repeatedly, attributes of alternatives and the alternatives themselves vary across choice sets.
} 


\section{Experimental data generation and sampling methods}

Parameter estimation requires paired household subscription-calling and rate data. These data are not available by distance-time band and statedpreference experimental data is used as an alternative data source. Details of the experimental data generation method, survey procedure and questionnaire design used in data collection is now outlined.

\subsection{The stated-preference and experimental design methods}

Stated-preference experiments define alternatives as collections of observed characteristics. Changing the level of some characteristic generates another alternative. The method requires households select the preferred alternative from a choice set of nondominant alternatives. An experiment is identified by the characteristics of the alternatives, the number and magnitudes of characteristic levels, the number of replications households' face, and the conjoint choice set generation process specified. ${ }^{9}$

Estimation of continuous/discrete models using stated-preference data requires that the experimental design, or at least the observation submatrix subject to the experimental design, is optimal for both the discrete choice and continuous models. Louviere and Woodworth (1983) establish a sufficient condition for parameter estimation of IIA (GEV and MNL) choice probabilities, that alternatives are pairwise independent (or orthogonal) across choice sets. Aigner (1979) and Conlisk (1973) demonstrate, for the linear and additive econometric regression model with an intercept, that mutual orthogonality among regressors is an optimal design plan. ${ }^{10}$ Subject

\footnotetext{
${ }^{9}$ More complex designs lead individuals to use simpler lexicographic non-trading choice rules. When a full factorial design generates a large number of choice sets the number is reduced by adopting a fractional factorial design. Fractional set design output is a minimum size incidence matrix (choice sets $\times$ alternatives) that enables full parameter estimation.

${ }^{10}$ The precision matrix for the model estimates is:
}

$$
\left(\sigma^{2} / n\right) M_{x x}^{-1}
$$

where

$$
M_{x x}=\left[\begin{array}{ccc}
1 & 0 & 0 \\
0 & m_{11} & m_{12} \\
0 & m_{21} & m_{22}
\end{array}\right] .
$$

and

$$
m_{i j}=(1 / n) \sum_{i=1}^{n}\left(m_{t i}-\bar{m}_{t i}\right)\left(m_{i j}-\bar{m}_{l j}\right) .
$$

Best estimates are obtained by applying the rule,

$$
\max \operatorname{det} M_{x x} \Leftrightarrow \min \operatorname{det} \frac{\left(\sigma^{2}\right)}{n} M_{x x}^{-1}
$$

referred to as D-optimality. 
to asymptotic approximation, Conlisk (1979) extends the optimal design criterion to the simultaneous equation model. Main-effects fractional factorial plans with symmetric orthogonal arrays provide the most parsimonious set of designs under which the continuous/discrete model optimality conditions apply to both the MNL and SUR estimators.

\subsection{An experimental calling rate structure set design for Australian telephone demand}

Conjoint methods provide the set of calling rate structures, the callminute price submatrix of the observation matrix for the calling demand system, from the set of experimental price levels. Separately priced distancetime calling bands with three call-minute price levels (high, medium, low), define $3^{13}$ different calling rate structures. ${ }^{11}$ All possible calling rate structures are represented by a $3^{13}$ full factorial design. Catalogue fractional factorial designs generate a matrix comprised of orthogonal calling rate structures. However, the method does not necessarily provide a spread of call-minute levels across rate structures that is diverse. A 16 treatmentcombination design is selected from the $3^{13}$ full factorial design by taking repeated random samples from the design with a random seed. The selected design represents a trade-off between the degree of orthogonality, dominance and a reasonable spread of call-minute price levels across rate structures.

The stated-preference experiment requires that households specify a preferred calling portfolio for some conjoint-generated calling rate structure. The household is informed of the calling expenditure 'incurred' under

${ }^{11}$ The following low, medium and high call-minute prices are used in the survey:

Experimental call-minute prices (cents/minute)

\begin{tabular}{lrrr}
\hline Day $0-10 \mathrm{~km}$ & 12 & 8 & 6 \\
Night $0-10 \mathrm{~km}$ & 6 & 4 & 2 \\
Day $10-30 \mathrm{~km}$ & 15 & 11 & 9 \\
Night $10-30 \mathrm{~km}$ & 9 & 7 & 3 \\
Day $30-100 \mathrm{~km}$ & 23 & 17 & 14 \\
Night $30-100 \mathrm{~km}$ & 14 & 11 & 8 \\
Economy $30-100 \mathrm{~km}$ & 8 & 7 & 4 \\
Day $100-800 \mathrm{~km}$ & 44 & 36 & 30 \\
Night $100-800 \mathrm{~km}$ & 30 & 24 & 19 \\
Economy $100-800 \mathrm{~km}$ & 19 & 14 & 7 \\
Day over $800 \mathrm{~km}$ & 66 & 57 & 48 \\
Night over $800 \mathrm{~km}$ & 48 & 38 & 28 \\
Economy over $800 \mathrm{~km}$ & 28 & 23 & 16 \\
\hline
\end{tabular}


the experiment and allowed to adjust the stated demands. The household is required to indicate whether network subscription is maintained at the experimental line rental charge. ${ }^{12}$ The experiment is repeated three times, the replications correspond to different calling rate structures.

\subsection{Survey procedure and questionnaire design}

These data are assumed generated by the trial of drawing a household at random from the single line telephone rental market segment of the population and recording the household's characteristics, experimental subscription-calling choicc and the corresponding rate structures. ${ }^{13}$ The sampling rule requires that a sequence of three independent trials, experimental calling rate structures, is presented to households renting a single line. The trial outcome is a $(j, m)$ pair chosen by the household from $J \times M$, the incidence space. $^{14}$

A predetermined sample size of 175 households ( 700 cases, three in-

${ }^{12}$ The following quarterly line rental fee options are used in the survey

Experimental line rental fees $(\$ /$ quarter $)$

\begin{tabular}{llllll}
\hline Low cost band & 15 & 20 & 25 & 30 & 35 \\
Medium cost band & 40 & 45 & 50 & 55 & 60 \\
High cost band & 65 & 70 & 75 & 80 & 85 \\
\hline
\end{tabular}

\footnotetext{
${ }^{13}$ Household characteristics capture the behavioural factors conditioning household choices. Telecom Australia Telephone Ownership surveys indicate the following households characteristics are useful to this study: (1) Number of residents in the household; (2) Number of workers in the household; (3) Home owned or paying rent; (4) Length of residence; (5) Ethnic origin of head of household; (6) Sex of head of household; (7) Age of head of household; (8) Occupation of head of household; (9) Employment status of head of household; (10) Years of schooling of head of household; (11) Self-employed or salaried head of household; (12) Telephone use subsidised or not.

${ }_{14}^{14}$ Telecom indicate the percentage of households not subscribed in the Sydney Metropolitan Area is approximately 5 percent, while the percentage of homes with multiple telephone line access is around 3 percent. The latter figure can be treated as an overstatement when allowance is made for the business calling on lines rented for residential use. The procedure used here is to redefine the universe and consider only the calling and line rental behaviour of the dominant single telephone line rental sector of the telephone line rental market. Modelling the single line market separately does require a reinterpretation of the estimating equations. The probability that a sampled houschold chooses single line subscription is interpreted as the likelihood that a currently single line subscribing household maintains subscription at experimental prices. The associated call minute demand equations for $0-10 \mathrm{~km}$ day calling is interpreted as the call demand for $0-10 \mathrm{~km}$ day calling by households that choose to retain subscription at experimental prices. Similar interpretations apply to other experimental subscription decisions and conditional calling demand equations.
} 
dependent trials and the base case for each household) is sampled by an exogenous stratified random sampling method. The stratification is by postcode number on the basis of socio-demographic characteristics. Sampling within each postcode area is by a simple random draw from the telephone directory. Households in the postcode area are contacted by telephone to arrange an appointment for interview.

The stated-preference experiment is implemented so as to obtain reasonable household experimental calling responses by controlling the experimental conditions. The experiment is controlled by first determining the households' current calling portfolio, evoked set, and then by presenting the household with rate structures only for currently called distance bands. Zero call demand is recorded for the distance bands not called in the households' current calling portfolio. 15

The approach causes the number of zero cases to dominate the number of positive cases in the dependent call demand vector for the over $30 \mathrm{~km}$ calling demands. For example, positive household demand for day calling to the Over $800 \mathrm{~km}$ calling band is reported for only 40 of the 700 cases.

\section{Results}

The telephone line-rental model provides the probability that a household will subscribe to the telephone network by renting a telephone line. The subscription probability, in (22) assumes the household has a binary choice of renting a line. The probability depends on factors that reflect the household's utility from telephone services and its ability to pay for the services. Socio-demographic variables are included in the estimating equation to capture factors that influence the utility derived from telephone services. Besides the household income variable, other socio-demographic variables entered in the line-rental equations include, the total number of persons (HHSIZE), the number of children under 14 years (AGE014), and the number of persons aged between 15 and 24 years residing in the household (AGE1524). Also included are dummy variables indicating whether the home is owned (HOMEOWN), the residence has been rented for less that one year (MOVERS), the head of household is the sole resident (SINGLE), the head of household is currently unemployed (UNMPLOY), the head of household is aged less than 25 years (HEADU25), the head of household is aged between 25 and 34 years (HEAD2534), the head of household is aged between 35 and 44 years (HEAD3544), the head of

\footnotetext{
${ }^{15}$ The assumption underlying the method is that households call bands where a calling population of known previous contacts is resident, irrespective of the calling rate structure However, call frequency or duration are reduced in the face of a higher call price. If the assumption is incorrect, estimated price elasticities understate the true elasticities.
} 
Table 1

Household telephone calling frequency.

\begin{tabular}{lcc}
\hline & $\begin{array}{c}\text { Household } \\
\text { average } \\
\text { quarterly call } \\
\text { demand } \\
\text { (minutes) }\end{array}$ & $\begin{array}{c}\text { Households with } \\
\text { non-zero demands } \\
\text { (maximum 700) }\end{array}$ \\
calling band & 856.3 & 626 \\
Day 0-10 km & 633.6 & 591 \\
Night $0-10 \mathrm{~km}$ & 304.8 & 497 \\
Day $10-30 \mathrm{~km}$ & 239.9 & 487 \\
Night $10-30 \mathrm{~km}$ & 77.4 & 132 \\
Day $30-100 \mathrm{~km}$ & 50.3 & 189 \\
Night $30-100 \mathrm{~km}$ & 7.8 & 65 \\
Economy $30-100 \mathrm{~km}$ & 30.7 & 100 \\
Day $100-800 \mathrm{~km}$ & 74.1 & 267 \\
Night $100-800 \mathrm{~km}$ & 25.0 & 118 \\
Economy $100-800 \mathrm{~km}$ & 21.5 & 40 \\
Day over $800 \mathrm{~km}$ & 18.5 & 96 \\
Night over $800 \mathrm{~km}$ & 9.2 & 56 \\
Economy over $800 \mathrm{~km}$ & & \\
\hline
\end{tabular}

household is aged between 45 and 54 years (HEAD4554), and the head of household is aged between 55 and 64 years (HEAD5564).

The elasticities of the line-rental probability with respect to call-minute prices and income are provided in Table 2 below. The signs of the line rental probability elasticities for the call-minute prices are negative for nine of the call-minute prices. All the estimates are inelastic and small in magnitude.

Table 2

Line rental call-minute price and income elasticities.

\begin{tabular}{lc}
\hline D10 & $-0.003^{*}$ \\
N10 & -0.0003 \\
D30 & 0.0004 \\
N30 & 0.0001 \\
D100 & $-0.002^{* *}$ \\
N100 & -0.0007 \\
E100 & $0.003^{* *}$ \\
D800 & -0.0008 \\
N800 & 0.002 \\
E800 & -0.0001 \\
D801 & -0.003 \\
N801 & $-0.003^{* *}$ \\
E801 & $-0.001^{* *}$ \\
INCOME & $0.0002^{*}$ \\
\hline
\end{tabular}

* Parameter is significant at the $5 \%$ level.

** Parameter is significant at the $10 \%$ level. 
Except for the day $0-10 \mathrm{~km}$ call-minute price, the absolute values of the $t$-ratios are less than two. The sign for the subscription probability income elasticities is positive, while the $t$-ratio is in excess of two.

Regarding the socio-demographic factors, none of the parameters are individually significantly different from zero at the 5 percent level. However, the likelihood ratio test for the joint hypothesis that the socio-demographic variables as a group do not add sufficient explanatory power to the model to compensate for the degrees of freedom utilised by the fuller specification is rejected at the 5 percent level. The model correctly predicts 96 percent of household subscription choices.

The calling demand equations are jointly estimated as a SUR system to allow for the cross-equation correlation caused by the household wealth constraint. Both the economic variables and socio-demographic variables specifications assume calling substitution between distance bands is implausible. The prices that matter to the household in determining a distance-time band quarterly calling demand is the call-minute price for the distance-time band and the call-minute prices for the same distance band but other time zones. Tables 3 and 4 below present the calling own and cross-price elasticity estimates for the socio-demographic variables specification of the model. Full results for this specification are shown in Appendix Table 1.

The own-price elasticities suggest that $0-30 \mathrm{~km}$ calling is price inelastic. Cross-price elasticities are smaller in magnitude than own-price elasticities for corresponding distance bands.

For over $30 \mathrm{~km}$ calling the negatively signed own-price elasticity estimates increase in magnitude with distance called. Economy Over $800 \mathrm{~km}$ calling is own-price elastic. Unlike the $0-30 \mathrm{~km}$ calling estimates there is no clear pattern suggesting cross-price elasticities are smaller than own-price elasticities.

The positively signed calling income elasticities provided in Table 5 above are inelastic. The negatively signed economy calling equations estimate supports the proposition that economy calls are regarded as an inferior good by subscribers.

Table 3

$0-30 \mathrm{~km}$ calling demand call-minute price elasticities.

\begin{tabular}{lcccc}
\hline $\begin{array}{l}\text { Distance-time } \\
\text { calling band }\end{array}$ & D10 & N10 & D30 & N30 \\
\hline Day 0-10 km & 0.05 & 0.04 & - & - \\
Night $0-10 \mathrm{~km}$ & -0.01 & -0.23 & - & - \\
Day $10-30 \mathrm{~km}$ & - & - & -0.40 & 0.16 \\
Night $10-30 \mathrm{~km}$ & - & - & -0.06 & $-0.46^{*}$ \\
\hline
\end{tabular}

\footnotetext{
* Parameter is significant at the $5 \%$ level.
} 


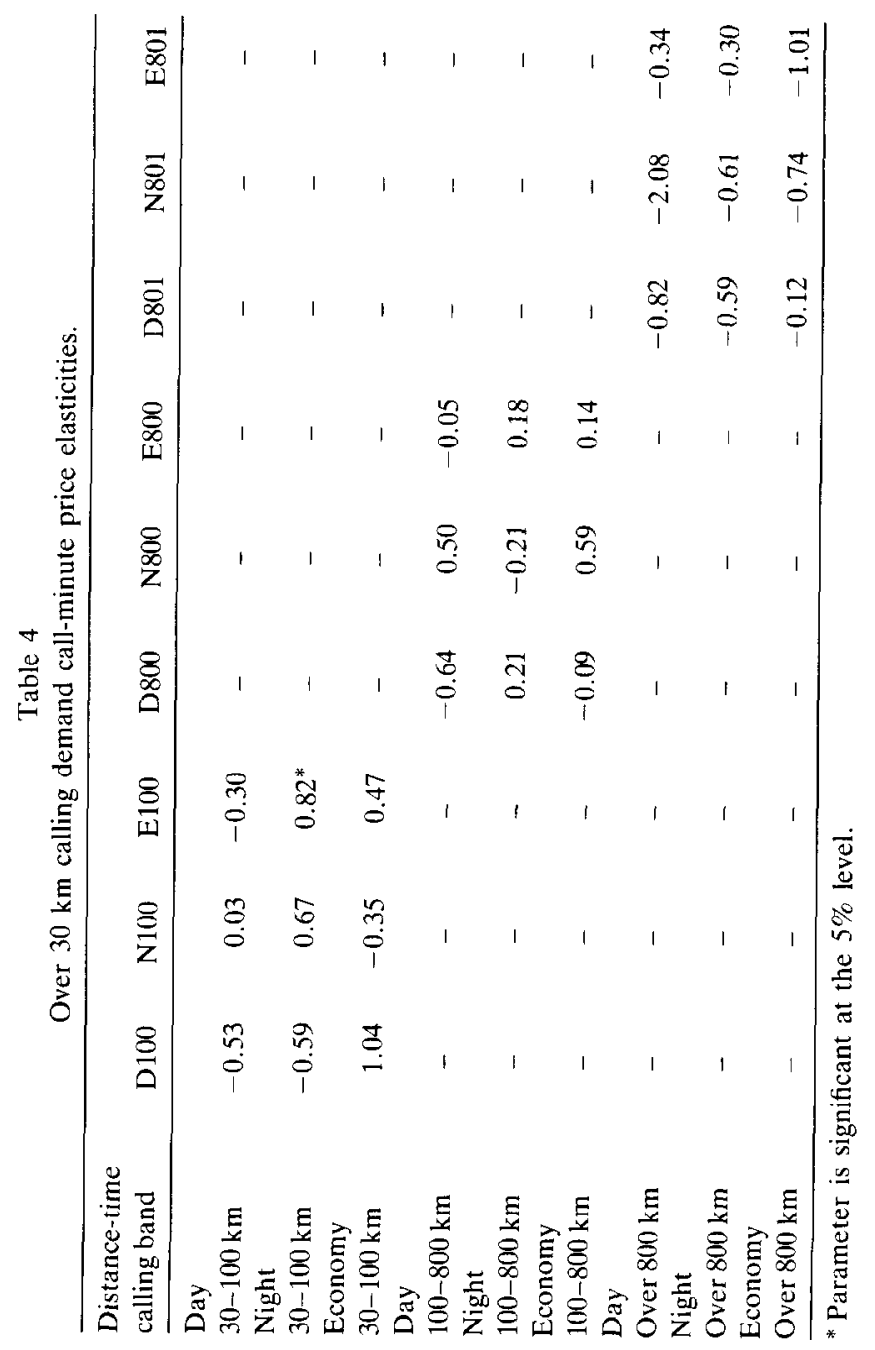


Table 5

Calling demand income elasticities.

\begin{tabular}{lc}
\hline Day $0-10 \mathrm{~km}$ & $0.46^{*}$ \\
Night $0-10 \mathrm{~km}$ & 0.25 \\
Day $10-30 \mathrm{~km}$ & 0.24 \\
Night $10-30 \mathrm{~km}$ & -0.08 \\
Day $30-100 \mathrm{~km}$ & 0.23 \\
Night $30-100 \mathrm{~km}$ & 0.03 \\
Economy $30-100 \mathrm{~km}$ & 0.33 \\
Day $100-800 \mathrm{~km}$ & 0.47 \\
Night $100-800 \mathrm{~km}$ & $0.90^{*}$ \\
Economy $100-800 \mathrm{~km}$ & -0.32 \\
Day over $800 \mathrm{~km}$ & 0.28 \\
Night over $800 \mathrm{~km}$ & $0.95^{*}$ \\
Economy over $800 \mathrm{~km}$ & $-1.06^{*}$ \\
\hline
\end{tabular}

* Parameter is significant at the $5 \%$ level.

The coefficients of the socio-demographic variables model represent the partial effect of each variable on household calling. For example, Park et al. (1983) and Kling and Van Der Ploeg (1990), study the effect of demographic variables on household local calling under a measured rate regime. The results of the studies regarding signs for the estimated coefficients are that large households reduce their calling relative to smaller households, that is, the number of persons resident in the household (HHSIZE) has a negative impact on local calling. However, given this effect an increase in the number of children and young adults resident in the household results in a greater demand for local telephone calls. The coefficients for the number of children resident in the household (AGE014) and the number of persons aged between 15 and 24 years resident in the household (AGE1524) are positive.

The results reported in Appendix Table 1 indicate that larger households have lower calling demands in 69 percent of the calling equations. The number of negatively signed coefficients is evenly spread over the five distance bands. The proportion of negatively signed coefficients is greatest for the day and night calling zones. Negatively signed coefficients are more often significant in the $0-30 \mathrm{~km}$ calling equations.

Day calling demand is lower for renting households that have recent tenure. There is no clear distance related pattern for the negatively signed coefficients.

Calling is greater in the region for households where the home is owner occupied. 77 percent of the estimated coefficients are positively signed in the equation. Day and night calling have 80 percent of the home ownership dummy variable coefficients positively signed.

The impacts on household calling demands of resident children and 
young adults resident are similar, with 77 percent of the estimated coefficients in the calling systems positively signed. $0-30 \mathrm{~km}$ calling is greater for the region with all of the estimated coefficients positively signed. Night calling volume is significantly greater when children are resident. Resident young adults significantly increase household local calling demand. Night and economy calling equations have 75 percent of the estimated coefficients positively signed while the day calling have 40 percent of the estimated coefficients positively signed.

Calling demands are smaller for households with a head under 25 years of age relative to those with head over 65 years for all the regions. The pattern holds for all calling distance bands. No general pattern is evident concerning the calling demands for households for other age heads relative to those with over 65 years of age heads.

A nested test of the economic and socio-demographic variable model specifications is made. The test rejects the joint hypothesis that the parameters of the socio-demographic variables are simultaneously zero, at the one percent level. The F-test performed is valid only for OLS, given the customary assumptions of the linear model. However, the test has good asymptotic properties for other estimation procedures including SUR.

Correlation between the household network subscription choice dummy variable and the random error term in the calling demand equations arises when unobserved factors influence both the household network subscription choice and the household calling demands. The problem is that the expectation of the disturbance term in the calling demand equations is not zero for each observation. This problem is addressed by including a selectivity correction variable in the calling demand equations to force the expectation of each disturbance term observation to zero. The proposition that subscription demand and calling demand for a particular distance-time band are interdependent is supported when the estimated coefficient on the selectivity correction variable is significantly different from zero. The structure of subscription and calling demand system interdependence is best observed by examining the pattern of significance for the correction variable through the calling demand system. The selectivity correction terms vary in significance by call distance. The $0-30 \mathrm{~km}$ call demand equations are associated with negative and significant selectivity coefficients for the endogeniety of line rental. Only $0-10 \mathrm{~km}$ night calling reveals no significant relationship between network use and the selectivity term, while calling for all distance bands over $30 \mathrm{~km}$ is not significantly related to the correction term.

Application of the Breusch-Pagan test to the OLS results rejects the homoskedasticity assumption in the calling demand equations. The standard errors of the estimated parameters are generally reduced using White's correction for heteroskedasticity. However, the changes in standard errors lead on average to a change in the significance category for only one 
estimated coefficient per equation. There is no clear pattern of change in significance by distance band.

A Wald test rejects the normality hypothesis for the regression residuals at the five percent level of significance. A subsequent examination of the standardised residuals indicates an average five percent of the residuals exceed two in absolute value, indicating possible outliers. In the absence of normality, small-sample tests of hypotheses developed using normality are no longer valid. However, $t$ - and F-tests are asymptotically valid if the errors are independent and identically distributed with zero mean and finitc variance. Further tests for functional form misspecification carried out indicate the test is significant for some of the equations. ${ }^{16}$

Another qualification about the reasonableness of the estimated parameters is that household call traffic is a decreasing function of distance. A minimum 25 percent of households report calling to the $0-10 \mathrm{~km}, 10-30 \mathrm{~km}$, $30-100 \mathrm{~km}$ and $100-800 \mathrm{~km}$ distance bands for each time zone, whereas calling is reported by less than 10 percent of the respondent households for the Over $800 \mathrm{~km}$ distance band.

\section{Conclusions}

Estimates of the impact of price, income and socio-demographic variables on line-rental and call-minute demand provide insights for telecommunications planning and policy. Demand responsiveness to prospective income and socio-demographic trends aids planning for system capacity, while demand responsiveness to price provides information for determining the consequences of unregulated pricing.

The income elasticity for line-rental demand reported in Table 2 is positive as are most of the income elasticities for call-minute demand reported in Table 5. This suggests continued growth in telecommunications demand in Australia as household incomes grow. The exceptional negative income elasticities for call-minute demand occur in the night and economy time periods, suggesting attempts to shift calling demand to off-peak times are hampered by income growth.

Call-minute demand is generally inelastic with respect to own price in the estimates reported in Table 3 and Table 4. An unregulated monopolist faced with inelastic demand would find it profitable to raise prices. This suggests some form of regulation or competition is required if prices are to be kept within the range covered by the survey questions, a range that brackets

\footnotetext{
${ }^{16}$ The equations and order of the Ramsey test rejected are as follows: Night, $0-10 \mathrm{~km}$, second, third and fourth order terms; Economy, 30-100 km, third and fourth order terms; Day, 100-800 km, fourth order term; Night, $100-800 \mathrm{~km}$, second, third and fourth order terms; Day, over $800 \mathrm{~km}$, second and fourth order terms; Night, over $800 \mathrm{~km}$, third and fourth order terms.
} 


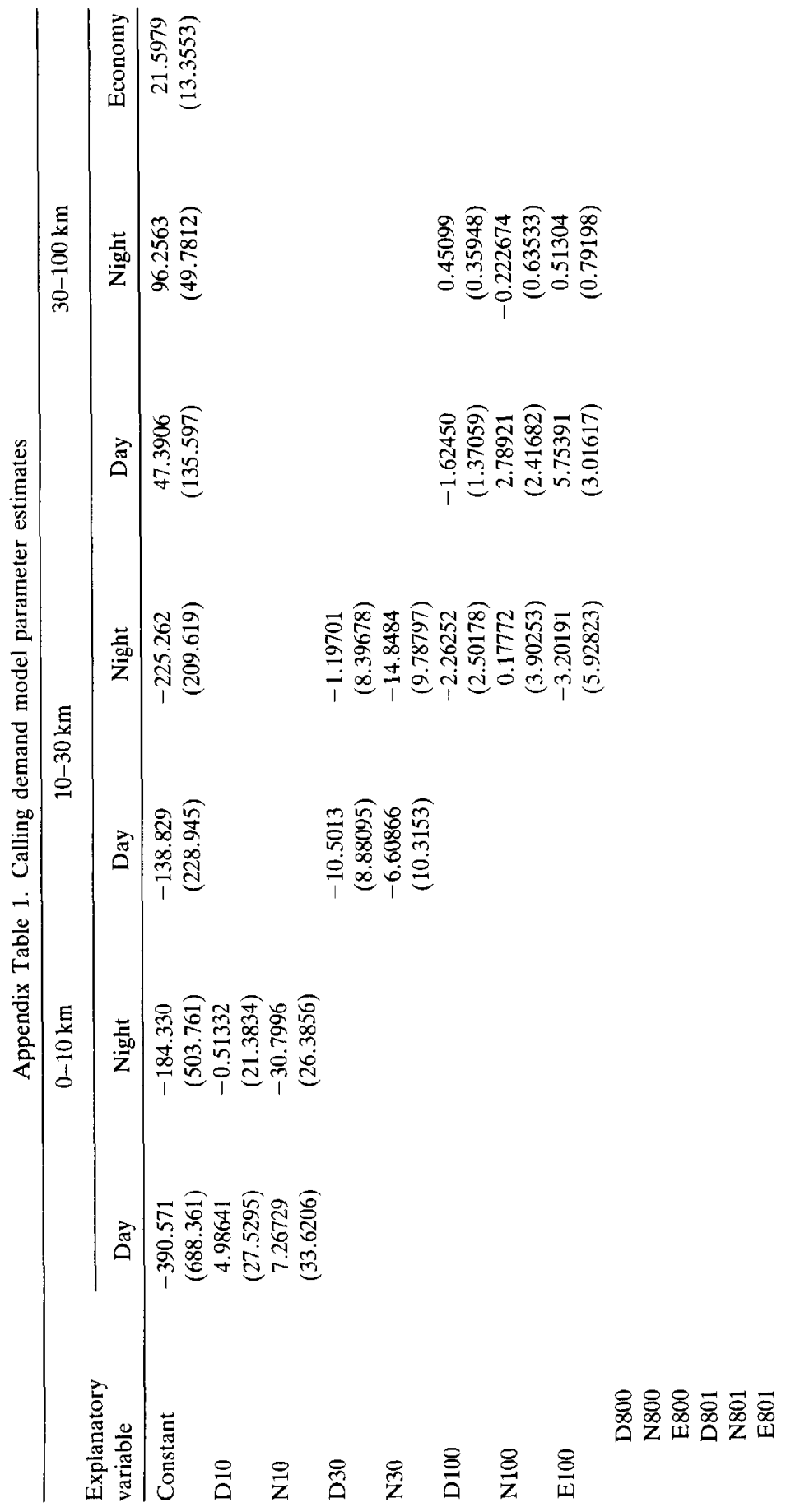




\begin{tabular}{|c|c|c|c|c|c|c|c|}
\hline INCOME & $\begin{array}{c}0.03919 \\
(0.01442)\end{array}$ & $\begin{array}{c}0.01568 \\
(0.01021)\end{array}$ & $\begin{array}{c}0.00734 \\
(0.00522)\end{array}$ & $\begin{array}{c}-0.00191 \\
(0.00473)\end{array}$ & $\begin{array}{c}0.00175 \\
(0.00339)\end{array}$ & $\begin{array}{c}0.00015 \\
(0.00121)\end{array}$ & $\begin{array}{c}0.00026 \\
(0.00032)\end{array}$ \\
\hline \multirow[t]{2}{*}{ HOMEOWN } & 534.818 & 176.708 & 47.3071 & 200.462 & 43.8724 & -7.12891 & -18.7213 \\
\hline & $(295.096)$ & $(214.282)$ & $(94.7719)$ & $(86.0966)$ & $(63.3866)$ & $(24.2834)$ & $(6.50130)$ \\
\hline \multirow[t]{2}{*}{ MOVERS } & 274.249 & -192.396 & -150.407 & 119.447 & -16.0376 & -39.9522 & -16.2389 \\
\hline & $(339.926)$ & $(243.661)$ & $(116.364)$ & $(105.643)$ & $(76.7857)$ & $(28.3889)$ & $(7.61507)$ \\
\hline \multirow[t]{2}{*}{ UNEMPLOY } & 329.356 & 846.474 & -295.537 & -400.885 & 90.7576 & 15.6750 & -0.99916 \\
\hline & $(413.916)$ & $(296.532)$ & $(141.919)$ & $(128.816)$ & $(93.3201)$ & (34.1196) & $(9.15820)$ \\
\hline \multirow[t]{2}{*}{ HHSIZE } & -322.433 & -101.851 & 5.45433 & -40.4207 & 4.53595 & -19.7086 & 1.73225 \\
\hline & (135.759) & $(96.0729)$ & $(49.2864)$ & $(44.7353)$ & $(31.9074)$ & $(11.3117)$ & (3.04174) \\
\hline \multirow[t]{2}{*}{ SINGE } & -395.117 & -40.8277 & -17.4811 & -59.6179 & -103.262 & -24.2510 & -1.32553 \\
\hline & $(244.963)$ & $(173.252)$ & $(89.0068)$ & $(80.7764)$ & $(57.7017)$ & $(20.4461)$ & $(5.49818)$ \\
\hline \multirow[t]{2}{*}{ AGE014 } & 448.991 & 298.469 & 42.0731 & 93.8861 & -30.5572 & 18.7844 & 1.05385 \\
\hline & $(140.028)$ & $(99.1044)$ & $(50.7778)$ & $(46.0863)$ & $(32.8949)$ & $(11.6622)$ & (3.13599) \\
\hline \multirow[t]{2}{*}{ AGE1524 } & 475.091 & 634.150 & 87.5261 & 175.929 & -41.1387 & -0.63020 & -4.44817 \\
\hline & $(150.347)$ & $(106.483)$ & $(54.3473)$ & $(49.3253)$ & $(35.2875)$ & $(12.5663)$ & (3.37818) \\
\hline \multirow[t]{2}{*}{ HEADU25 } & -624.370 & -394.434 & -78.2973 & 19.5060 & 39.8043 & -17.7580 & -8.28893 \\
\hline & $(461.158)$ & $(328.694)$ & $(162.248)$ & $(147.285)$ & $(105.623)$ & $(37.9643)$ & $(10.2001)$ \\
\hline \multirow[t]{2}{*}{ HEAD2534 } & 63.3164 & 306.147 & 177.706 & 385.350 & 40.1438 & -1.10715 & -4.50312 \\
\hline & $(351.390)$ & $(252.801)$ & $(118.605)$ & $(107.719)$ & $(78.3252)$ & $(29.2150)$ & $(7.83290)$ \\
\hline \multirow[t]{2}{*}{ HEAD3544 } & 424.863 & 185.070 & 233.368 & 318.398 & 44.0194 & -17.3391 & 17.1146 \\
\hline & $(321.817)$ & $(231.352)$ & $(108.995)$ & $(98.9864)$ & $(71.8021)$ & $(26.6239)$ & $(7.14051)$ \\
\hline \multirow[t]{2}{*}{ HEAD4554 } & 415.787 & 220.331 & 197.805 & 216.827 & 141.238 & -16.3898 & -5.73007 \\
\hline & $(313.276)$ & $(224.994)$ & $(106.321)$ & $(96.5297)$ & $(70.3684)$ & $(26.1726)$ & $(7.01830)$ \\
\hline \multirow[t]{2}{*}{ HEAD5564 } & 636.050 & 308.005 & 260.815 & 295.707 & 145.898 & -14.4526 & -3.59891 \\
\hline & (313.644) & $(225.180)$ & $(106.894)$ & $(97.0682)$ & $(70.5110)$ & $(26.1588)$ & $(7.01554)$ \\
\hline \multirow[t]{2}{*}{ Correction } & -78.7569 & -39.6151 & -22.7487 & -25.5763 & 0.76546 & 3.79673 & 0.81415 \\
\hline & $(33.1615)$ & $(24.4638)$ & $(9.68910)$ & $(8.81070)$ & $(6.7645)$ & $(2.77502)$ & $(0.74033)$ \\
\hline
\end{tabular}


Appendix Table 1 (continued)

\begin{tabular}{|c|c|c|c|c|c|c|}
\hline \multirow{2}{*}{$\begin{array}{l}\text { Explanatory } \\
\text { Variable }\end{array}$} & \multicolumn{3}{|c|}{$100-800 \mathrm{~km}$} & \multicolumn{3}{|c|}{ Over $800 \mathrm{~km}$} \\
\hline & Day & Night & Economy & Day & Night & Economy \\
\hline Constant & $\begin{array}{c}69.8790 \\
(65.4319)\end{array}$ & $\begin{array}{r}-79.5895 \\
(96.2353)\end{array}$ & $\begin{array}{c}26.7234 \\
(41.2924)\end{array}$ & $\begin{array}{c}141.454 \\
(118.143)\end{array}$ & $\begin{array}{c}1.6297 \\
(34.0951)\end{array}$ & $\begin{array}{c}3.0418 \\
(25.5964)\end{array}$ \\
\hline $\begin{array}{r}\text { D10 } \\
\text { N10 } \\
\text { D30 } \\
\text { N30 } \\
\text { D100 } \\
\text { N100 } \\
\text { E100 }\end{array}$ & & & & & & \\
\hline D800 & $\begin{array}{c}-0.53861 \\
(0.93545)\end{array}$ & $\begin{array}{c}0.42087 \\
(1.37167)\end{array}$ & $\begin{array}{c}-0.06410 \\
(0.58922)\end{array}$ & & & \\
\hline N800 & $\begin{array}{c}0.59701 \\
(1.68625)\end{array}$ & $\begin{array}{c}-0.61420 \\
(2.47171)\end{array}$ & $\begin{array}{c}0.58003 \\
(1.06530)\end{array}$ & & & \\
\hline E800 & $\begin{array}{c}-0.10019 \\
(1.35602)\end{array}$ & $\begin{array}{c}0.87536 \\
(1.99146)\end{array}$ & $\begin{array}{c}0.23352 \\
(0.85820)\end{array}$ & & & \\
\hline D801 & & & (0.80994) & $\begin{array}{c}-0.31240 \\
(0.33004)\end{array}$ & $\begin{array}{c}-0.19337 \\
(0.24819)\end{array}$ & -0.01937 \\
\hline N801 & & & $(1.03180)$ & $\begin{array}{c}-1.17380 \\
(0.31633)\end{array}$ & $\begin{array}{c}-0.29461 \\
(0.23582)\end{array}$ & -0.17950 \\
\hline E801 & & & (1.18801) & $\begin{array}{c}-0.32105 \\
(0.48123)\end{array}$ & $\begin{array}{r}(-0.24315) \\
(0.36214)\end{array}$ & -0.41162 \\
\hline INCOME & $\begin{array}{c}0.00145 \\
(0.00122)\end{array}$ & $\begin{array}{c}0.00670 \\
(0.00181)\end{array}$ & $\begin{array}{c}-0.00081 \\
(0.00077)\end{array}$ & $\begin{array}{c}0.00061 \\
(0.00234)\end{array}$ & $\begin{array}{c}0.00176 \\
(0.00053)\end{array}$ & $\begin{array}{c}-0.00099 \\
(0.00040)\end{array}$ \\
\hline
\end{tabular}




\begin{tabular}{|c|c|c|c|c|c|c|}
\hline HOMEOWN & $\begin{array}{c}-45.6398 \\
(22.0714)\end{array}$ & $\begin{array}{c}46.6969 \\
(32.5776)\end{array}$ & $\begin{array}{c}5.0022 \\
(13.9258)\end{array}$ & $\begin{array}{c}0.52564 \\
(42.1490)\end{array}$ & $\begin{array}{c}6.03944 \\
(9.54262)\end{array}$ & $\begin{array}{c}2.68941 \\
(7.21940)\end{array}$ \\
\hline MOVERS & $\begin{array}{r}-15.6717 \\
(27.2699)\end{array}$ & $\begin{array}{c}308.749 \\
(40.2518)\end{array}$ & $\begin{array}{c}23.5837 \\
(17.2059)\end{array}$ & -17.6357 & $\begin{array}{c}1.23246 \\
(11.7832)\end{array}$ & $\begin{array}{r}9.98726 \\
(8.91483)\end{array}$ \\
\hline UNEMPLOY & $\begin{array}{c}-26.4230 \\
(33.4373)\end{array}$ & $\begin{array}{c}-32.7497 \\
(49.3530)\end{array}$ & $\begin{array}{c}-34.3309 \\
(21.0969)\end{array}$ & $\begin{array}{c}-0.78876 \\
(63.7193)\end{array}$ & $\begin{array}{c}5.40860 \\
(14.4365)\end{array}$ & $\begin{array}{c}-15.3123 \\
(10.9216)\end{array}$ \\
\hline HHSIZE & $\begin{array}{c}-6.54186 \\
(11.5641)\end{array}$ & $\begin{array}{c}-23.3763 \\
(17.0694)\end{array}$ & $\begin{array}{c}-5.61851 \\
(7.29629)\end{array}$ & $\begin{array}{c}-19.2041 \\
(22.1110)\end{array}$ & $\begin{array}{c}-21.6170 \\
(5.00147)\end{array}$ & $\begin{array}{c}1.20011 \\
(3.78403)\end{array}$ \\
\hline SINGLE & $\begin{array}{c}-38.9134 \\
(20.9501)\end{array}$ & $\begin{array}{c}91.9561 \\
(30.9233)\end{array}$ & $\begin{array}{c}-7.34322 \\
(13.2183)\end{array}$ & $\begin{array}{c}-57.6298 \\
(39.9907)\end{array}$ & $\begin{array}{c}-5.32212 \\
(9.04177)\end{array}$ & $\begin{array}{c}3.43442 \\
(6.84090)\end{array}$ \\
\hline AGE014 & $\begin{array}{c}1.40488 \\
(11.9261)\end{array}$ & $\begin{array}{c}36.9007 \\
(17.6037)\end{array}$ & $\begin{array}{c}12.1802 \\
(7.52469)\end{array}$ & $\begin{array}{c}0.59222 \\
(22.7979)\end{array}$ & $\begin{array}{c}20.3296 \\
(5.15758)\end{array}$ & $\begin{array}{c}3.08656 \\
(3.90214)\end{array}$ \\
\hline AGE1524 & $\begin{array}{c}6.86164 \\
(12.7727)\end{array}$ & $\begin{array}{c}9.29661 \\
(18.8531)\end{array}$ & $\begin{array}{c}5.77545 \\
(8.05890)\end{array}$ & $\begin{array}{c}-17.7150 \\
(24.3946)\end{array}$ & $\begin{array}{c}32.2995 \\
(5.51399)\end{array}$ & $\begin{array}{c}5.80545 \\
(4.17183)\end{array}$ \\
\hline HEADU25 & $\begin{array}{c}-22.6779 \\
(38.1759)\end{array}$ & $\begin{array}{c}-57.2041 \\
(56.3468)\end{array}$ & $\begin{array}{c}-42.9383 \\
(24.0868)\end{array}$ & $\begin{array}{c}8.13230 \\
(72.7087)\end{array}$ & $\begin{array}{c}-36.6208 \\
(16.4479)\end{array}$ & $\begin{array}{c}2.46924 \\
(12.4441)\end{array}$ \\
\hline HEAD2534 & $\begin{array}{c}-3.96970 \\
(27.6943)\end{array}$ & $\begin{array}{c}67.8663 \\
(40.8779)\end{array}$ & $\begin{array}{c}-16.0730 \\
(17.4736)\end{array}$ & $\begin{array}{c}-3.76333 \\
(52.9335)\end{array}$ & $\begin{array}{c}17.1664 \\
(11.9827)\end{array}$ & $\begin{array}{c}6.24748 \\
(9.06527)\end{array}$ \\
\hline HEAD3544 & $\begin{array}{c}28.5625 \\
(25.4683)\end{array}$ & $\begin{array}{c}40.1723 \\
(37.5922)\end{array}$ & $\begin{array}{c}-17.1985 \\
(16.0691)\end{array}$ & $\begin{array}{c}20.5480 \\
(48.6624)\end{array}$ & $\begin{array}{c}6.99981 \\
(11.0143)\end{array}$ & $\begin{array}{c}-4.01359 \\
(8.33279)\end{array}$ \\
\hline HEAD4554 & $\begin{array}{c}19.9444 \\
(24.9183)\end{array}$ & $\begin{array}{c}61.6077 \\
(36.7802)\end{array}$ & $\begin{array}{c}-17.9513 \\
(15.7220)\end{array}$ & $\begin{array}{c}99.5780 \\
(47.6370)\end{array}$ & $\begin{array}{c}31.2376 \\
(10.7861)\end{array}$ & $\begin{array}{c}-0.27614 \\
(8.15988)\end{array}$ \\
\hline HEAD5564 & $\begin{array}{c}49.5196 \\
(25.0725)\end{array}$ & $\begin{array}{c}57.3304 \\
(37.0064)\end{array}$ & $\begin{array}{c}3.04139 \\
(15.8195)\end{array}$ & $\begin{array}{c}-10.4590 \\
(47.8331)\end{array}$ & $\begin{array}{c}4.62505 \\
(10.8362)\end{array}$ & $\begin{array}{c}-11.0952 \\
(8.19745)\end{array}$ \\
\hline Correction & $\begin{array}{c}0.39556 \\
(2.23589)\end{array}$ & $\begin{array}{c}-0.19266 \\
(3.30013)\end{array}$ & $\begin{array}{c}-0.82295 \\
(1.41073)\end{array}$ & $\begin{array}{c}-1.12591 \\
(4.27133)\end{array}$ & $\begin{array}{c}0.34559 \\
(0.96954)\end{array}$ & $\begin{array}{c}1.03504 \\
(0.73341)\end{array}$ \\
\hline
\end{tabular}


current Telecom Australia charges. It is interesting to note that the highest estimated own-price elasticities occur for the longest distance band, with demand having a slightly higher than unitary elasticity for economy calling in this distance band. Removal of regulation would apparently provide the least incentive for price increases for calling over the longest distances.

\section{References}

Aigner, D.J., 1979, A brief introduction to the methodology of optimal experimental design, Journal of Econometrics 11 7-26.

Atherton, T., M. Ben-Akiva, D. McFadden and K. Train, 1990, Micro-simulation of local residential telephone demand under alternative service options and rate structures, in: $A$. de Fontenay, M.H. Shuggard and D.S. Sibley, eds., Telecommunications demand modelling (North-Holland, Amsterdam) 137-163.

Ben-Akiva, M. and S.R. Lerman, 1985, Discrete choice analysis: theory and application to travel demand (MIT Press, Cambridge, MA).

Conlisk, J., 1973, Choice of response functional form in designing subsidy experiments, Econometrica $41643-656$.

Conlisk, J., 1979, Design for simultaneous equations, Journal of Econometrics $1163-76$.

Dubin, J.A. and D. McFadden, 1984, An econometric analysis of residential electric appliance holdings and consumption, Econometrica 52 345-362.

Dubin, J.A., 1985, Consumer durable choice and the demand for electricity (North-Holland, Amsterdam).

I lanemann, W.M., 1984, Discrete/continuous models of consumer demand, Econometrica 52 $541-561$.

Kling, J.P. and S.S. Van der Ploeg, 1990, Estimating local call elasticities with a model of stochastic class of service and usage choice, in: A. de Fontenay, M.H. Shuggard and D.S. Sibley, eds., Telecommunications demand modelling (North-Holland, Amsterdam) 119136.

Louviere, J.J. and G. Woodworth, 1983, Design and analysis of simulated consumer choice or allocation experiments: an approach based on aggregate data, Journal of Marketing Research 20, 350-367.

McFadden, D., 1974, Conditional logit analysis of qualitative choice behaviour, in: P. Zarembka, ed., Frontiers in econometrics (Academic Press, New York) 105-142.

Mitchell, B.M., 1978, Optimal pricing of local telephone service, American Economic Review $68517-537$.

Pacey, P.L., 1983, Long distance demand: a point to point model, Southern Economic Journal 49 1094-1107.

Park, R.E., B.M. Wetzel and B.M. Mitchell, 1983, Price elasticities for local telephone calls, Econometrica 51 1699-1730.

Squire, L., 1973, Some aspects of optimal pricing for telecommunication, The Bell Journal of Economics and Management Science 4 515-525.

Taylor, L.D. and D. Kridel, 1990, Residential demand for access to the telephone network, in: A. de Fontenay, M.H. Shuggard and D.S. Sibley, eds., Telecommunications demand modelling (North-Holland, Amsterdam) 105-117.

Train, K., 1986, Qualitative choice analysis: theory, econometrics and application to automobile demand (MIT Press, Cambridge, MA).

Train, K., D. McFadden and M. Ben-Akiva, 1987, The demand for local telephone service: a fully discrete model of residential calling patterns and service choices, The Rand Journal of Economics 18 109-123. 